\title{
Biosorption of phenol and 2-chlorophenol by Funalia trogii pellets
}

\author{
Gulay Bayramoglu ${ }^{\mathrm{a}, *}$, Ihsan Gursel $^{\mathrm{b}}$, Yagmur Tunali ${ }^{\mathrm{c}}$, M. Yakup Arica ${ }^{\mathrm{a}}$ \\ ${ }^{a}$ Gazi University, Faculty of Arts and Sciences, Biochemical Processing and Biomaterial Research Laboratory, 06500 Teknik Okullar, Ankara, Turkey \\ ${ }^{\mathrm{b}}$ Bilkent University, Molecular Biology and Genetics Department, Bilkent 06800, Ankara, Turkey \\ c Anadolu University, Faculty of Pharmacy, Department of Pharmaceutical Microbiology, 26470 Tepebaşı, Eskişehir, Turkey
}

\section{A R T I C L E I N F O}

Article history:

Received 27 September 2008

Received in revised form 22 December 2008

Accepted 23 December 2008

Available online 30 January 2009

\section{Keywords:}

Funalia trogii

Phenol

Bioremediation

Adsorption kinetic

Adsorption isotherm

\begin{abstract}
A B S T R A C T
The removal of phenol $(\mathrm{Ph})$ and 2-chlorophenol (2-CPh) from aqueous solution by native and heat inactivated fungus Funalia trogii pellets were investigated. The effects of contact time, solid/liquid ratio, optimum $\mathrm{pH}$ and temperature on the phenols removal capacity by the pellets were established. The removal efficiency of phenols increased significantly with increasing biomass dose. The optimum $\mathrm{pH}$ was detected to be 8.0. The second-order equations are described and evaluated on the basis of a comparative estimation of the corresponding coefficients. The phenol removal equilibrium isotherm was modeled by the Langmuir equations. The enthalpy change values were obtained between -7.62 and $-10.64 \mathrm{~kJ} / \mathrm{mol}$. This indicated that the uptake of phenols either on native or heat inactivated fungal pellets was based on a physical adsorption process.
\end{abstract}

(c) 2008 Elsevier Ltd. All rights reserved.

\section{Introduction}

Phenols are widely distributed as environmental pollutants. Treatment of industrial wastewaters contaminated with phenolic compounds is a daunting problem. They exist in different concentrations in wastewaters disposed from many industrial processes, including petrochemical industry, coking, synthetic rubber, plastics, paper, oil refineries, as well as phenolic resin industries (Bayramoglu and Arica, 2008; Tepe and Dursun, 2008). Wastewater containing phenolic compounds presents a serious discharge problem due to their poor biodegradability, high toxicity and long term ecological damage. Due to the high toxicity of phenols, they are strictly regulated, and their industrial use is increasingly avoided by substituting them with harmless compounds. The Environmental Protection Agency (EPA) calls for lowering phenol content in the wastewater to less than $1 \mathrm{mg} / \mathrm{ml}$ (Hallenbeck and Cunningham, 1986). Wastewaters containing phenols and other toxic compounds need careful treatment before discharge into the receiving large bodies of water reservoirs. Biological treatment, activated carbon adsorption, solvent extraction, chemical oxidation and electrochemical methods are the most widely used methods for removing phenol and phenolic compounds from wastewaters (Ra et al., 2008). Problems such as high cost, low efficiency, and generation of toxic by-products are limiting factors for wide applications of some of these remediation strategies.

\footnotetext{
* Corresponding author. Tel.: +90 312202 1142; fax: +90 3122122279.

E-mail addresses: g_bayramoglu@hotmail.com, gbayramoglu@gazi.edu.tr (G. Bayramoglu).
}

Among various physicochemical processes adsorption technology is extensively studied in recent years (Li et al., 2004). However, due to economic restraints, there is a growing interest in the preparation and use of low cost and unconventional adsorbents ( $\mathrm{Wu}$ and Yu, 2007; Akar et al., 2008). The use of microorganisms such as algae, bacteria and fungi with the special surface properties for the biosorption of metallic and organic pollutants from contaminated solutions has long been studied on the laboratory scale and in field studies (Bayramoglu and Arica, 2009; Arica and Bayramoglu, 2005; Navarro et al., 2008). For example, phenol, 2-chlorophenol, and 4-chlorophenol have been effectively removed using a brown algae Sargassum muticum. 2,4-Dichlorophenol has been biosorbed from aqueous solutions by non-living fungal pellets of Phanerochaete chrysosporium (Aranda et al., 2006; Sampedro et al., 2007), and bacterial strains such as Achromobacter sp. and Escherichia coli (Quan et al., 2004).

The present study is designed to examine effective and low cost phenol and 2-chlorophenol removal by native or heat inactivated Funalia trogii pellets. The selected organism offers several advantages over already studied counterparts. While it forms a substantially high biomass for removal of toxic heavy chemicals from aqueous solutions, it also readily grows on cheap carbon sources (i.e., cellulose) and possesses several extra-cellular enzymes for bioremediation of various xenobiotics. In order to evaluate removal mechanism and kinetics, the effects of the removal parameters such as: (i) $\mathrm{pH}$, (ii) temperature, (iii) equilibrium time and (iv) effect of phenolic compound concentrations on the removal efficiency were investigated. 


\section{Methods}

\subsection{Microorganism and media}

Pure culture of $F$. trogii (MAFF 430012) was obtained from MAFF GENE BANK Culture Collection (Kannondai, Tsukuba, Ibaraki, Japan), and was maintained by subculturing on malt dextrose agar slants. The growth medium and growth conditions for white rot fungi were previously described elsewhere (Arica et al., 2004). The cultivated fungus pellets of $F$. trogii were washed with sterile physiological saline solution several times to remove debris and undesirable particles. In some experiments pellets were heat inactivated (at $90^{\circ} \mathrm{C}$ for $15 \mathrm{~min}$ ) and used as such in phenol removal assays.

\subsection{Phenolic solutions}

Phenol and 2-chlorophenol were obtained from Sigma and used without further purification. A stock solution was prepared by dissolving $1.0 \mathrm{~g}$ of $\mathrm{Ph}$ and $2-\mathrm{CPh}$ in $1.0 \mathrm{l}$ of purified water. The concentrations of phenolic compounds for experiments were adjusted between 30 and $600 \mathrm{mg} / \mathrm{l}$. The $\mathrm{pH}$ of several test solutions was set to range between 2.0 to 11.0 at the start of each experiment.

\subsection{Degradation of phenol and 2-chlorophenol}

F. trogii was grown in a medium containing ( $\mathrm{g} / \mathrm{l})$ glucose, 10.0; $\mathrm{KH}_{2} \mathrm{PO}_{4}, 2.0 ; \mathrm{MgSO}_{4} \cdot 7 \mathrm{H}_{2} \mathrm{O}, 0.5 ; \mathrm{CaCl}_{2}, 0.1 ; \mathrm{NH}_{4} \mathrm{Cl}, 0.12$ and thiamine, 0.001 cultured on an orbital shaker at $100 \mathrm{rpm}$ at $\mathrm{pH} 5.0$ and at $30^{\circ} \mathrm{C}$ for 6 days. After this period, the biomass was collected and rinsed and fungal mycelia (about $2 \mathrm{~g}$ on dry basis) were transferred into $250 \mathrm{ml}$ flask containing fresh culture medium $(100 \mathrm{ml})$ as described above that was supplemented with phenol and/or 2chlorophenol $(500 \mathrm{mg} / \mathrm{l})$ instead of glucose. A $0.5 \mathrm{ml}$ sample was removed and then $1.0 \mathrm{ml}$ hexane was added to extract the remaining phenols in the culture medium. The phenolic compound concentration was determined by HPLC using these aliquots.

\subsection{Analysis and biosorption studies}

The biosorption of phenols onto the native and heat inactivated fungal pellet was investigated in a water jacketed batch reactor (inner volume: $150 \mathrm{ml}$ ). The reactor temperature was controlled with a thermo-circulator. Preliminary experiments demonstrated that when the biomass was incubated at $30^{\circ} \mathrm{C}$ at $100 \mathrm{rpm}$ for $24 \mathrm{~h}$ the adsorption had reached equilibrium.

The concentration of the phenolic compounds in the aqueous phase was measured by high performance liquid chromatography, HPLC (Dionex Co., Germering, Germany). The chromatographic determination of phenols was achieved on a Supelco C-8, HPLC column $(150 \mathrm{~mm} \times 4.6 \mathrm{~mm}$ i.d.; $5 \mu \mathrm{m})$ protected by a guard column (Supelco C-8; $20 \mathrm{~mm} \times 4.0 \mathrm{~mm}$ i.d.). All sample solutions used in chromatographic studies were pre-filtered by a $0.2 \mu \mathrm{m}$ membrane filter (Millipore). HPLC mobile phases A and B were prepared by adding acetic acid $(0.1 \%)$ to methanol and acetic acid $(0.1 \%)$ to Milli $\mathrm{Q}$ water, respectively. The mobile phases were filtered prior to use. The chromatographic determination was performed using a gradient at $1.5 \mathrm{ml} / \mathrm{min}$ flow-rate (in $0-20 \mathrm{~min}$; phase A from $35 \%$ to $100 \%$ and phase B from $65 \%$ to $0 \%$ and return to phase $A$ and $B$ $35 \%$ and $65 \%$ in $5 \mathrm{~min}$, respectively) and the sample injection volume of the auto sampler was $20 \mu$ l. The UV-visible detector was set at 270 and $274 \mathrm{~nm}$ for phenol and 2-chlorophenol and the temperature was maintained at $30^{\circ} \mathrm{C}$. Dionex CHROMELLEON ${ }^{\circledR}$ software was used and operated under Windows for data acquisition and integration.
Biosorption of phenols (i.e., phenol and 2-chlorophenol) from aqueous solutions onto native or heat inactivated fungal pellets were investigated in batch system and the amount of removed phenols was calculated as the difference between initial and final phenol concentrations.

To examine the effect of solid/liquid ratio (w/v) various amount of biosorbents on dry basis (between 0.25 and $2.0 \mathrm{~g} / \mathrm{l}$ ) was used in a $100 \mathrm{ml}$ phenol containing solutions (concentration was adjusted to $200 \mathrm{mg} / \mathrm{l}$ phenol). The effects of $\mathrm{pH}$ and temperature on the removal performance of the fungal pellets were examined at $\mathrm{pH}$ value between 2.0 and 11.0 (by the addition of dilute $\mathrm{HCl}$ or $\mathrm{NaOH}$ solutions). Four different temperatures were selected for the study $\left(15,25,35\right.$ and $\left.45^{\circ} \mathrm{C}\right)$. During adsorption assays, $6 \mathrm{~h}$ of incubation was found to be optimum. The effect of the initial phenol concentrations on biosorption was studied as noted above except that the concentration of phenols in the sorption medium varied between 30 and $600 \mathrm{mg} / \mathrm{l}$.

The amount of biosorbed phenols per unit fungal biomass ( $\mathrm{mg}$ phenols/g dry biomass) was obtained by using the following expression:

$q=\left[\left(C_{o}-C\right) \cdot V\right] / m$

where $q$ is the amount of phenols biosorbed onto the unit amount of the biomass $(\mathrm{mg} / \mathrm{g}) ; C_{o}$ and $C$ are the concentrations of the phenols in the initial solution $(\mathrm{mg} / \mathrm{l})$ and after biosorption, respectively; $V$ is the volume of the aqueous phase ( 1 ) and $m$ is the amount of the biomass $(\mathrm{g})$. The average of three repeat experiments is presented in the results.

\subsection{Determination of desorption efficiency}

In order to determine the desorption efficiency of the fungal preparation biomass, consecutive adsorption-desorption cycles were repeated three times by using the same biosorbent. Desorption was achieved by using methanol solution (25\%; v/v). Phenol and 2-cholorophenol loaded $F$. trogii biomasses were placed in this desorption medium and stirred at $200 \mathrm{rpm}$ for $2 \mathrm{~h}$ at room temperature. After eluting, the biomass was regenerated by washing with water. The final concentration in the aqueous phase was determined by using a HPLC as described before.

\subsection{Evaluation of equilibrium biosorption isotherms}

The Langmuir and Redlich-Peterson equations were used to define adsorption isotherms. The Langmuir equation is represented by the following expression:

$q_{e}=q_{m} b C_{e} / 1+b C_{e}$

where $C_{e}$ and show the residual phenols concentration $(\mathrm{mg} / \mathrm{l})$ and $q_{e}$ the amount of phenolic compounds sorbed on the biosorbent at equilibrium $(\mathrm{mg} / \mathrm{g}), b$ is the energy of sorption or sorption equilibrium constant $(1 / \mathrm{mg})$ of the system, and $q_{m}$ is the maximum adsorption capacity. The equilibrium parameter, $R L$, is used to predict if an adsorption system is "favorable" or "unfavorable". It is obtained by the following relationship:

$R L=1 / 1+b C_{o}$

where $C_{o}$ is the initial phenols concentration. The value of RL indicates the shape of isotherm to be either (i) unfavorable $(R L>1)$, (ii) linear $(R L=1)$, (iii) favorable $(0<R L<1)$, and (iv) irreversible $(R L=0)$. The Freundlich equation is:

$q_{e}=K_{F}\left(C_{e}\right)^{1 / n}$

where $K_{F}$ and $n$ are the Freundlich constants, and they are the indicators of the "adsorption capacity" and "adsorption intensity", respectively. 
The three-parameters of Redlich-Peterson equation was proposed to improve the fit by the Langmuir or Freundlich equation and is given by Eq. (5) (Redlich and Peterson, 1959):

$q_{e q}=K_{R P} C_{e q} / 1+a_{R P} C_{e q}^{\beta}$

where $K_{R P}, a_{R P}$ and $\beta$ are the Redlich-Peterson parameters. The exponent $\beta$ lies between 0 and 1 . For $\beta=1$, the Eq. (5) converts to the Langmuir form.

\subsection{Characterization of surface properties of fungal biomass preparation}

The surface area of the native and heat inactivated $F$. trogii pellets were determined by Brunauer-Emmett-Teller (BET) equation using a surface area apparatus (Model Flowsorb II 2300; Micromeritics Instrument Corporation, Norcross, USA). The dried fungal pellets were coated with gold under reduced pressure and their scanning electron micrographs were obtained using a JEOL (JSM 5600 ) scanning electron microscope. FT-IR spectra of powdered native and heat inactivated fungal pellets were obtained by using a FT-IR spectrophotometer (Mattson 1000 FT-IR, England). The dry fungal biomass (about $0.1 \mathrm{~g})$ mixed with $\mathrm{KBr}(0.1 \mathrm{~g})$ and pressed into a tablet form. The FT-IR spectrum was then recorded.

\subsection{Potentiometric titration}

A $2.0 \mathrm{~g}$ of native and heat inactivated fungal biomass was suspended in $\mathrm{KCl}$ solution $(0.1 \mathrm{M}, 50 \mathrm{ml})$ to maintain a stable ionic strength during the potentiometric titration studies. Each titration was made by duplicates at $25{ }^{\circ} \mathrm{C}$ under nitrogen atmosphere. Native and heat inactivated fungal biomass were titrated by standard solutions of $0.1 \mathrm{~N} \mathrm{NaOH}$ (basic branch) and $0.1 \mathrm{~N} \mathrm{HCl}$ (acid branch). After each addition of titrant ( $\mathrm{NaOH}$ or $\mathrm{HCl}$ ), the $\mathrm{pH}$ of suspension was allowed to reach equilibrium by mixing and then measured by a $\mathrm{pH}$ meter.

\subsection{Contact angle studies and calculation of surface energy}

The native, heat inactivated and their phenols adsorbed counterpart biomass films on glass surface were prepared and contact angles against different test liquids (i.e., water, glycerol and DIM) were measured by sessile drop method at $25^{\circ} \mathrm{C}$ by using a digital optical contact angle meter CAM 200 (KSV Instruments Ltd., Helsinki, Finland). The sessile drop was formed by depositing the liquid from the above using a manual micro-syringe on the biomass surface. The measurements were accumulated by taking the average of 10 contact angles at least operated on two biomass samples as described previously (Bayramoglu et al., 2004).

The surface free energy parameters of the native and heat inactivated biomass and their phenol and 2-cholorophenol adsorbed counterpart biomasses were calculated using the contact angle data of the probe liquids. The results were analyzed according to van Oss acid-base method (van Oss, 2003). The relevant equations are summarized below.

The total surface free energy, $\gamma^{T O T}$, can be divided two components, where

$\gamma^{T O T}=\gamma^{L W}+\gamma^{A B}$

$L W$ is the dispersive component of the surface free energy associated with Lifshitz-van der Walls interaction, reflecting the long range interactions (including the dispersive interaction, the dipole-dipole interaction, and dipole-induced dipole interaction, which is dominated by the dispersion), was calculated from the measured diiodomethane contact angles, and $\gamma^{\mathrm{AB}}$ designated such acid-base interactions as hydrogen bonding, and $\gamma^{+}$and $\gamma^{-}$refer to proton and electron donating characters, respectively. Substituting the appropriate expressions, the Eq. (7) is obtained:

$$
(1+\cos \theta) \gamma_{l}=2\left[\left(\gamma_{s}^{L W} \cdot \gamma_{l}^{L W}\right)^{1 / 2}+\left(\gamma_{s}^{+} \cdot \gamma_{s}^{-}\right)^{1 / 2}+\left(\gamma_{s}^{-} \cdot \gamma_{l}^{+}\right)^{1 / 2}\right]
$$

The known parameter values of three liquids and their contact angles on biomass sample were used in Eq. (7) and the method equation was solved using CAM 200 software packages operated under Windows 98 (KSV Instruments Ltd.).

\section{Results and discussion}

\subsection{Properties of the fungal biomass}

The functional groups for phenolic compounds binding on the fungal cell walls are several, and includes hydrophobic and hydrophilic [such as carboxyl $(-\mathrm{COOH})$, phosphate $\left(\mathrm{PO}_{4}^{3-}\right)$, primary and secondary amines $\left(-\mathrm{NH}_{2},=\mathrm{NH}\right)$, thiol $(-\mathrm{SH})$, and hydroxide $(-\mathrm{OH})]$. In fungal cell walls, chitin and its associated proteins contain many carboxyl groups with $\mathrm{p} K_{\mathrm{a}}$ values in the range of 4.0-5.0 (Rostami and Joodaki, 2002; Arica and Bayramoglu, 2005; Zeng et al., 2007). The mechanisms of phenol and 2-chlorophenol removal by native and heat inactivated fungus pellets were elucidated on the basis of heat treatment; potentiometric titration, FT-IR spectra, SEM, BET methods as well as contact angle studies. Heat treatment can modify surface binding sites via denaturation of proteins on the cell wall structures. The changes in the functional groups and the surface properties of the fungal pellets are confirmed by the FT-IR spectra before and after heat treatment (data not shown). FT-IR spectra of native and heat inactivated fungus confirm the biosorbents heterogeneity and provide evidence for the presence of different characteristic peaks in agreement with the possible presence of amino, carboxylic, hydroxyl and carbonyl groups. In general, the FT-IR spectra of the native and heat inactivated fungal biomass have intense peaks at the frequency level of $3400-3250 \mathrm{~cm}^{-1}$ representing -OH stretching of carboxylic groups and also representing stretching of -NH groups. The strong peaks at around $1648 \mathrm{~cm}^{-1}$ are caused by the bending of $\mathrm{N}-\mathrm{H}$ groups of chitin on the cell wall structure of fungal pellets. The peak at $1917 \mathrm{~cm}^{-1}$ is observed in the fingerprint region representing aromatic ring substitution overtones. The peaks at 2931, 1548, 1397 , 1168 and $1047 \mathrm{~cm}^{-1}$ representing $\mathrm{C}-\mathrm{H}$ stretching vibrations, $\mathrm{N}-\mathrm{H}$ bending (scissoring), $-\mathrm{CH}_{3}$ wagging (umbrella deformation), symmetric $-\mathrm{SO}_{3}$ stretching and $\mathrm{C}-\mathrm{OH}$ stretching vibrations, respectively, which were due to several functional groups present on the fungal cell walls. The peak at 573 and $541 \mathrm{~cm}^{-1}$ representing $\mathrm{O}-\mathrm{C}-\mathrm{O}$ scissoring and $\mathrm{C}-\mathrm{O}$ bending vibrations are only observed for the native fungal biomass and these peaks was not seen for the heat inactivated counterpart can be due to the removal of lipid compounds following heat treatment. The band at $487 \mathrm{~cm}^{-1}$ representing $\mathrm{C}-\mathrm{N}-\mathrm{C}$ scissoring is found in polypeptide structure.

The surface morphology and bulk structure of the dried fungal pellets from native organism was studied by the scanning electron micrograph, and the fungal pellets have fibrous and porous surface structures (data not shown). These surface properties can be considered as a factor providing an increase in the total surface area. In addition, the fibrous and pores structures of the fungal pellets could reduce the diffusional resistance and facilitate mass transfer because of their high internal surface area. The surface areas of the native and heat inactivated fungal pellets were measured by BET method and were found to be 1.47 and $1.13 \mathrm{~m}^{2} / \mathrm{g}$, respectively. The surface areas of the fungal biomass were decreased after heat treatment compared to native form.

\subsection{Potentiometric titration and acid-base properties}

In order to understand the removal of phenol and 2-chlorophenol from aqueous solutions, the apparent ionization constant $\left(\mathrm{p} K_{\mathrm{a}}\right)$ 
of both native and heat inactivated fungal biomass and the total concentration of acidic groups expressed like carboxyl groups were determined by potentiometric titration. Previous studies have determined that environmental polluting agents are mostly attracted to specific functional groups present in fungal biomass (Mukhopadhyay, 2008) and in other biosorbents (Dunlap et al., 2005) such as weakly acidic carboxyl, sulfone and phosphate groups. The other functional groups on the fungal cell walls are the secondary and primary amino groups of chitin and chitosan, respectively. These experimentally obtained data were indicative of the influence of $\mathrm{pH}$ on deprotonation of groups on the fungal cell surface. For $\mathrm{pH}$ values greater than the $\mathrm{p} K_{\mathrm{a}}$, the sites were mainly in a dissociated form and can exchange $\mathrm{H}^{+}$with target adsorbate in solution. At a $\mathrm{pH}$ lower than $\mathrm{p} K_{\mathrm{a}}$ values, the complexation phenomena occurred especially due to the $\mathrm{COO}^{-}$groups (Naja et al., 2005). A titration curve was generated to characterize the interaction of the biomass with hydrogen or sodium ions (data not shown). The acid-base titration provided more information about the functional groups and assisted in defining more precisely the number of active sites at a given $\mathrm{pH}$ and these functional groups removed phenol and 2-chlorophenol from aqueous solutions.

\subsection{Degradation of phenol and 2-chlorophenol}

Phenol and/or 2-chlorophenol degradation assays were carried out with $2 \mathrm{~g}$ of wet live fungal pellets in $100 \mathrm{ml}$ medium. The initial content of phenol and/or 2-chlorophenol was $500 \mathrm{mg} / \mathrm{l}$. At the end of 6 days of incubation, the remaining phenol and 2-chlorophenol concentrations were determined by HPLC. F. trogii decreased the phenol and 2-chlorophenol content of the medium after 6 days of treatment about $79 \pm 9.3 \%$ and $85 \pm 7.7 \%$, respectively. No further significant decrease was observed in the phenols content of medium by the fungus tested after 6 days. The assays carried out in minimal medium show that the $F$. trogii was capable of degrading phenol and 2-chlorophenol both individually.

\subsection{Effect of contact time, $\mathrm{pH}$, biosorbent dosage, initial phenol concentrations onto biosorption of phenols}

The amounts of biosorbed phenolic compounds increased with time, and saturation levels were reached at $6 \mathrm{~h}$ (data not shown). The biosorption amounts of phenolic compounds were very high at the beginning of biosorption. The 2-chlorophenol was adsorbed faster than phenol on both native and heat inactivated fungal biomass. This is due to much higher affinity of the biomass towards 2chlorophenol.

Literature data on the biosorption kinetics of phenolic compounds when different sources of sorbents were used showed a wide range of equilibrium adsorption rates. For example, the rapid adsorption rate obtained in this study is in agreement with the results of Kennedy et al. (1992) and Calace et al. (2002), in which the time required for equilibrium was 3 and 2 h, respectively.

Biosorption of phenol and 2-chlorophenols by the native and heat inactivated $F$. trogii biomass preparations were investigated in the $\mathrm{pH}$ range from 2.0 to 11.0 at $25^{\circ} \mathrm{C}$. The phenolic compounds considered in this study, phenol and 2-chlorophenol, have a $\mathrm{p} K_{\mathrm{a}}$ of 9.9 and 8.3, respectively. Therefore, both phenol and 2-chlorophenol exist predominantly as neutral species at around $\mathrm{pH}$ 8.0. The interaction between the fungal biomass preparation and phenolic derivatives is considered mainly as non-polar, and the forces responsible for adsorption are physical van der Waals forces. As seen in Fig. 1, phenol and 2-chlorophenol adsorption capacities of the fungal preparations were increased with increasing $\mathrm{pH}$ from 2.0 to 8.0. The maximum biosorption of both phenol and 2-chlorophenol was observed at $\mathrm{pH}$ between 8.0 and 9.0 for fungal biomass preparations. To account for the observed behavior, some addi-

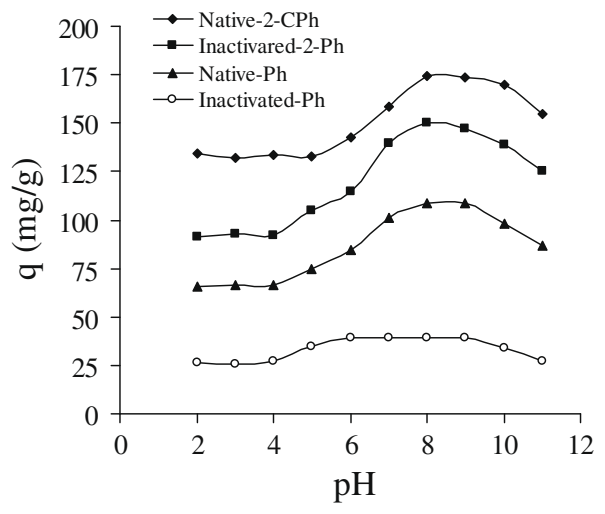

Fig. 1. Effect of $\mathrm{pH}$ on the biosorption capacities of the native and heat inactivated biomass of Funalia trogii. Biosorption conditions: initial concentration of phenols: $200 \mathrm{mg} / \mathrm{l}$; volume of biosorption medium: $100 \mathrm{ml}$; temperature: $25^{\circ} \mathrm{C}$; and biosorption time: $6 \mathrm{~h}$.

tional types of retention mechanisms should be contemplated, including donor-acceptor interactions between the aromatic ring activated by the $-\mathrm{OH}$ and $-\mathrm{Cl}$ substituents and the groups of the biosorbents surface, and interactions of phenols with the fungal mycelia by complex formation or the distribution of phenol and 2-chlorophenol which are neutral species, between the aqueous solution and the wall cell structure of the fungal cellular membranes. It should be noted that the numerous hydroxyl groups that remain protonated during the experimental conditions possessed a strong dipole $\mathrm{O}-\mathrm{H}$ that were able to form three hydrogen bonds. These are strengthened at high $\mathrm{pH}$ values, if the molecule to be adsorbed (like phenol) is also charged. Similar observations were reported previously, for example, the biosorption of phenols by the marine seaweeds Lessonia nigrescens Bory and Macrocystis integrifolia Bory was investigated as a function of initial solution $\mathrm{pH}$, showing a higher adsorption capacities at around pH 10 (Navarro et al., 2008).

The dependence of phenol biosorption on biosorbents dose was studied by varying the amount of adsorbents from 0.25 to $2.0 \mathrm{~g} / \mathrm{l}$ while keeping other parameters constant such as $\mathrm{pH} 8.0$, agitation speed at $100 \mathrm{rpm}$, and contact time ( $6 \mathrm{~h}$ ). It was observed that percentage removal of phenols by the biosorbents generally improved with increasing biomass dose (the data not shown). This is expected due to the fact that the higher dose of biosorbents in the solution provided higher available binding sites for the phenolic compounds. To perform the remaining biosorption experiments, $0.25 \mathrm{~g}$ of fungal biomass was selected.

\subsection{Kinetic modeling for biosorption system}

The second-order rate equation of Ritchie is used for the sorption of solute from a liquid solution. It may be represented as follows (Ritchie, 1997):

$\left(1 / q_{t}\right)=\left(1 / k_{2} q_{e q} t\right)+\left(1 / q_{e q}\right)$

where $k_{2}\left(\mathrm{~g} \mathrm{mg}^{-1} \mathrm{~min}^{-1}\right)$ is the rate constant of pseudo-second-order adsorption.

The experimental maximum biosorption capacities of the native fungal biomass for phenol and 2-chlorophenol were $132.6 \mathrm{mg} / \mathrm{g}$ and $289.1 \mathrm{mg} / \mathrm{g}$. On the hand, the biosorption capacities for phenol and 2-chlorophenol on heat inactivated counterpart were 42.4 and $204.3 \mathrm{mg} / \mathrm{g}$, respectively. The native fungal biomass has higher adsorption capacity for both phenols compared to heat inactivated counterpart. The experimental results obtained for the biosorption of phenols on fungal biomass preparations were found to obey the second-order kinetic. The pseudo-second-order equation at differ- 
Table 1

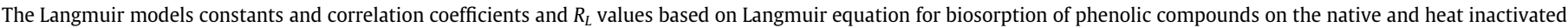
fungal biomass at $25^{\circ} \mathrm{C}$.

\begin{tabular}{|c|c|c|c|c|c|}
\hline Phenolic compounds & $q_{e}\left(\mathrm{mg} \mathrm{g}^{-1}\right)$ & $q_{m}\left(\mathrm{mg} \mathrm{g}^{-1}\right)$ & $b \times 10^{2}(1 / \mathrm{mg})$ & $R^{2}$ & $R_{L}^{\mathrm{a}}$ \\
\hline Inactive-Ph & 42.4 & 47.6 & 1.00 & 0.991 & 0.330 \\
\hline Native-Ph & 132.6 & 147.0 & 1.88 & 0.990 & 0.210 \\
\hline Inactive-2-CPh & 204.3 & 227.3 & 2.74 & 0.999 & 0.155 \\
\hline Native-2-CPh & 289.1 & 312.5 & 4.04 & 0.996 & 0.110 \\
\hline
\end{tabular}

a Shows the $R_{L}$ value calculated at $200 \mathrm{mg} / \mathrm{l}$ initial phenolic compounds concentration.

ent temperatures fitted well with the experimental data for phenolic compounds (data not shown). The pseudo-second-order model is based on the assumption that the rate determining step may be a chemical sorption involving valence forces through sharing or exchange of electrons between sorbents and sorbate (Ho, 2006).

\subsection{Evaluated isotherm models and related parameters of the biosorption process}

To examine the relationship between sorbed $\left(q_{e}\right)$ and aqueous concentration $\left(C_{e}\right)$ at equilibrium, sorption isotherm models are widely employed for fitting the data. For this reason, the Langmuir and Freundlich equations are used. Table 1 present the Langmuir adsorption constants and the correlation coefficients that are calculated from the semi-reciprocal plots. The conformity of the biosorption data to the Langmuir isotherm could be interpreted as indicating a homogenous adsorption process, leading to monolayer binding with constant adsorption energy. Based on the effect of separation factor, " $R L$ values" are in the range of $0<R L<1$. This indicates that the $F$. trogii biomass used in the present study are indeed a favorable biosorbents for phenol removal from aqueous solution (Table 1 ). The results also showed that besides the Langmuir model, Freundlich and Redlich-Peterson models are also suitable for describing the biosorptions of phenols. As seen from Table $2, n$ values were found to be high enough for separation of heavy metal ions from aqueous medium. Related Redlich-Peterson adsorption parameters calculated according to the three-parameter isotherm of Redlich-Peterson were tabulated in Table 2 for phenolic compounds at $25{ }^{\circ} \mathrm{C}$. Redlich-Peterson constant $K_{R P}$ also imply that the biosorption capacity of biomass (with the following order from highest to lowest capacity): 2-CPh-native $>2$-CPh-heat inactivated $>\mathrm{Ph}$-native $>\mathrm{Ph}$-heat inactivated. The exponent $\beta$ was between 0.734 and 0.975 of the phenol biosorptions, showing the closeness of the model to the Langmuir isotherm. It should be noted that $\beta$ normally lie between 0 and 1, indicating a favorable biosorption for each phenolic compounds.

\subsection{Thermodynamic parameters for biosorption system}

The biosorption capacities of the fungal preparation decreases for both phenols with the increasing temperature, showing an exothermic adsorption process. Activation energy is determined according to pseudo-second-order rate constant. It is expressed as a function of temperature by the Arrhenius equation, $k=A_{o} \exp \left(-E_{a} / R T\right) . A_{o}$ is the temperature independent factor, $k$ is the second-order rate constant and $R$ is the gas constant $(8.314 \mathrm{~J} /$ $\mathrm{mol} / \mathrm{K})$. Value of the activation energy, $E_{a}$, can be determined from the slope of $\ln k$ versus $1 / T$ plot. The activation energies for phenol and 2-chlorophenol on the native and heat inactivated fungal biomass were calculated and the values were found to be -1.21 and -5.21 for $\mathrm{Ph}$, and -6.99 and $-6.32 \mathrm{~kJ} / \mathrm{mol}$ for $2-\mathrm{CPh}$, respectively. The magnitude of activation energy may give an idea about the type of sorption. The magnitude of activation energy is mostly lower than that of $8.0 \mathrm{~kJ} / \mathrm{mol}$ indicating physical biosorption.

Thermodynamic parameters such as standard free energy change $(\Delta G)$, standard enthalpy change $\left(\Delta H^{\circ}\right)$ and standard entropy change $\left(\Delta S^{\circ}\right)$ were also obtained. The Gibbs free energy change of adsorption process was calculated by using the following equation:

$\Delta G^{\circ}=-R T \ln K_{a}$

where $K_{a}$ is the dependency of the equilibrium association constant ( $K_{a}=b$, from Langmuir constant). $T$ is the solution temperature. Standard enthalpy and entropy change values of biosorption can be calculated from van't Hoff equation given as below:

$\ln K_{a}=\left(\Delta S^{\circ} / R\right)-\left(\Delta H^{\circ} / R T\right)$

The thermodynamic parameters for phenolic compounds biosorbed on the fungal preparation were calculated for different temperatures. When the temperature increased from $288 \mathrm{~K}$ to $318 \mathrm{~K}, \Delta G^{\circ}$ decreased (from -17.0 to $-22.6 \mathrm{~kJ} / \mathrm{mol}$ ) for the used phenolic compounds. The negative of $\Delta G^{\circ}$ values at given temperatures indicates the spontaneous nature of the biosorption and confirms the energy free feasibility of the biosorption process. The negative value of $\Delta H^{\circ}$

Table 3

Contact angles of various test liquids for native and heat inactivated fungal biomasses.

\begin{tabular}{llll}
\hline Biomass form & $\begin{array}{l}\text { Water } \theta\left(^{\circ}\right) \\
\left(\gamma_{\text {erg }}=71.3\right)\end{array}$ & $\begin{array}{l}\text { Glycerol } \theta\left(^{\circ}\right) \\
\left(\gamma_{\text {erg }}=64.0\right)\end{array}$ & $\begin{array}{l}\text { DIM } \theta\left(^{\circ}\right) \\
\left(\gamma_{\text {erg }}=50.8\right)\end{array}$ \\
\hline Native & 95.3 & 92.3 & 56.2 \\
Heat inactivated & 73.8 & 81.9 & 41.4 \\
Native-Ph & 95.9 & 92.4 & 46.1 \\
Heat inactivated-Ph & 91.8 & 86.7 & 48.8 \\
Native-Ph & 94.7 & 87.6 & 45.4 \\
Heat inactivated-Ph & 91.3 & 82.4 & 46.5 \\
\hline
\end{tabular}

$\gamma_{\text {erg: }}$ Surface tension of test liquid.

Table 2

The Freundlich and Redlich Peterson models constants and correlation coefficients for biosorption of phenolic compounds on the biomass preparations at $25{ }^{\circ} \mathrm{C}$.

\begin{tabular}{|c|c|c|c|c|c|c|c|}
\hline \multirow[t]{2}{*}{ Phenolic compounds } & \multicolumn{3}{|c|}{ Freundlich constants } & \multicolumn{4}{|c|}{ Redlich-Peterson constants } \\
\hline & $n$ & $K_{F}$ & $R^{2}$ & $a_{R P}(\mathrm{l} / \mathrm{g})$ & $K_{R P}(1 / \mathrm{mg})^{\beta}$ & $\beta$ & $R^{2}$ \\
\hline Inactive-Ph & 2.79 & 6.53 & 0.992 & 0.063 & 2.00 & 0.901 & 0.978 \\
\hline Native-Ph & 2.31 & 13.59 & 0.943 & 0.085 & 5.21 & 0.734 & 0.957 \\
\hline Inactive-2-CPh & 2.04 & 18.76 & 0.960 & 0.857 & 9.06 & 0.857 & 0.994 \\
\hline Native-2-CPh & 2.23 & 34.39 & 0.979 & 0.558 & 30.67 & 0.975 & 0.982 \\
\hline
\end{tabular}


Table 4

Surface free energy parameters $\left(\mathrm{mJ} / \mathrm{m}^{2}\right)$ of the native and heat inactivated biomass according to the van Oss.

\begin{tabular}{|c|c|c|c|c|c|c|}
\hline Biomass & $\gamma^{L W}\left(\mathrm{mN} / \mathrm{m}^{2}\right)$ & $\gamma^{+}\left(\mathrm{mN} / \mathrm{m}^{2}\right)$ & $\gamma^{-}\left(\mathrm{mN} / \mathrm{m}^{2}\right)$ & $\gamma^{A B}\left(\mathrm{mN} / \mathrm{m}^{2}\right)$ & $\gamma^{T O T}\left(\mathrm{mN} / \mathrm{m}^{2}\right)$ & Polarity (\%) \\
\hline Native & 29.12 & 0.07 & 2.05 & 3.97 & 33.82 & 11.7 \\
\hline Heat inactivated & 41.88 & 0.34 & 4.59 & 11.59 & 53.47 & 21.7 \\
\hline
\end{tabular}

a Polarity $(\%)=\left(\gamma^{A B} \times 100\right) / \gamma^{T O T}$.

is an implication of the exothermic nature of the biosorption process. The value range from -8.13 to $-10.64 \mathrm{~kJ} / \mathrm{mol}$ indicated that the uptake process of phenols on biomass is a physical mode of adsorption. However, for 2-CPh, the biosorption enthalpy change is larger than that of $\mathrm{Ph}$, this means that the interaction between 2- $\mathrm{CPh}$ and biosorbent surface is much stronger than $\mathrm{Ph}$ and led to an augmented biosorption rate. Fungal pellets interacted with 2$\mathrm{CPh}$ molecules provided high-energy sorption sites thus, the enthalpy became more negative. Positive $\Delta S^{\circ}$ values for phenol and 2chlorophenol biosorption were found to be 31.3 and $40.3 \mathrm{~kJ} / \mathrm{mol} \mathrm{K}$ and for the native 36.5 and $38.8 \mathrm{~kJ} / \mathrm{mol} \mathrm{K}$ for heat inactivated biomass, respectively, indicate an increase in degree of freedom of the phenol species.

\subsection{Contact angle studies and calculation of surface energy}

Contact angle measurements with three probe liquids were used to characterize the surfaces of native and heat inactivated fungal biomass and their phenol and 2-chlorophenol adsorbed counterparts. Contact angle behavior was determined for water, glycerol and diiodomethane (DIM). The results are reported in Table 3. The highest contact angles were obtained with water. The contact angle value after heat treatment showed that the hydrophilicity of the fungal biomass increased compared to native biomass. The phenol adsorbed surfaces of both fungal preparations were hydrophobic (i.e. $\theta>90^{\circ}$ ) as shown by contact angle measurement. As mentioned earlier, native $F$. trogii had more functional groups on the cell wall and most of them were removed after heat treatment. Therefore, the native fungal biomass donated more available adsorptive side on the surfaces as presented in Table 3. After loosing their hydrophobic moieties, as expected, biosorption capacity of the heat inactivated fungal biomass was decreased for phenol and 2-chlorophenol compared to native form. From these observations, hydrophobic interaction is important as well as charge-charge interactions and could be responsible from the increased adsorption of phenolic species on the native fungal biomass preparations.

The determined overall surface free energy $\left(\gamma^{T O T}\right)$ was calculated by using the van Oss method, consisting of the sum of the Lifshitzvan der Waals $\left(\gamma^{L W}\right)$ and the acid-base components $\left(\gamma^{A B}\right)$ applies for all investigated fungal preparations at different values. As can be seen from Table 4, all investigated fungal preparations showed different acid-base components $\left(\gamma^{A B}\right)$ of the surface energy $\left(\gamma^{T O T}\right)$ due to different chemical structures of the native and inactivated fungal cell surfaces. The polar components $\left(\gamma^{A B}\right)$ of the native and heat inactivated fungal cells could be broken down into a large base $\left(\gamma^{-}\right)$ and very small acid $\left(\gamma^{+}\right)$surface energy components, yielding about 2.05 and $4.59 \mathrm{mN} / \mathrm{m}^{2}$, respectively. These results suggest that the surface of the white rot fungus $F$. trogii is best described as a basic $\left(\gamma^{-}\right)$monopolar surface. As expected, the highest $\gamma^{A B}$ value was observed from the heat inactivated fungal biomass. This could be due the removal of hydrophobic lipid portion of cell wall components during heat treatment process. Therefore, the polarity of the heat inactivated fungal biomass increased up to $21.7 \%$ (Table 4). From this result, heat treatment of fungal biomasses resulted an increased polar and its subcomponent of the surface free energy. The hydrophobic interaction was more pronounced between the native biomass and phenolic compounds under the given conditions and the native fungal biomasses yielded higher adsorption capacities than that of the heat inactivated form.

\subsection{Desorption efficiency}

Desorption experiments were performed with methanol solution $(25 \%, v / v)$ as the desorption agent. The fungal biomass preparations were placed within desorption medium and the amount of phenol or 2-chlorophenol desorbed in $2 \mathrm{~h}$ was determined by HPLC. The amounts of desorbed phenol or chlorophenol from fungal biomass preparations were found to be $83.8 \pm 3.6$ and $79.3 \pm 2.9$, respectively. This means that methanol is a suitable desorption agent to break down the interaction forces between phenols and functional binding sites onto the surface of the fungal biomass preparations.

\section{Conclusion}

The FT-IR and potentiometric titration studies show evidence that $\mathrm{pH}$ could act exclusively on the ionization state of the functional groups of both fungal preparations in aqueous solution. In addition, a maximum adsorption was determined at around $\mathrm{pH} 8$ for both tested fungal biomasses. Throughout the present study, combined with infrared spectroscopy and degradation studies, as well as the acid-base titration and contact angle assays allowed us to characterize the functional adsorptive sites of $F$. trogii pellets. It should be noted that metabolically active uptake of phenolic compounds by the native fungal pellets have a significant impact on the removal of phenolic compounds from aqueous solutions. $\mathrm{Fi}$ nally, we have developed a native biomass pellet composed of $F$. trogii biomass, and presented substantial supportive data concerning batch phenols removal in addition to theoretical thermodynamic parameters contributing this process. The simple and low cost generation of the biosorbent and its efficient and effective toxic compound removal capacities provide a potential tool for applying this strategy for wide range bioremediation protocols.

\section{Acknowledgements}

We are gratefully to the financial support provided by the Turkish Science and Technology Research Council (TUBITAK-TBAG104T365).

\section{References}

Akar, T., Ozcan, A.S., Tunali, S., Ozcan, A., 2008. Biosorption of a textile dye (Acid Blue 40) by cone biomass of Thuja orientalis: estimation of equilibrium, thermodynamic and kinetic parameters. Bioresource Technology 99, 30573065.

Aranda, E., Sampedro, I., Ocampo, J.A., García-Romera, I., 2006. Phenolic removal of onative-mill dry residues by laccase activity of white-rot fungi and its impact on tomato plant growth. International Biodeterioration \& Biodegradation 58, $176-179$.

Arica, M.Y., Bayramoglu, G., 2005. Cr(IV) biosorption from aqueous solution using free and immobilized biomass of Lentinus sajor-caju: preparation and kinetic characterization. Colloids and Surface A: Physicochemical and Engineering Aspects 253, 203-211.

Arica, M.Y., Bayramoglu, G., Yilmaz, M., Bektas, S., Genc, O., 2004. Biosorption of $\mathrm{Hg}^{+2}, \mathrm{Cd}^{+2}$ and $\mathrm{Zn}^{+2}$ by Ca-alginate and immobilized wood-rotting fungus Funalia trogii. Journal of Hazardous Materials B 109, 191-199. 
Bayramoglu, G., Arica, M.Y., 2009. Construction a hybrid biosorbent using Scenedesmus quadricauda and Ca-alginate for biosorption of $\mathrm{Cu}(\mathrm{II}), \mathrm{Zn}$ (II) and $\mathrm{Ni}(\mathrm{II})$ : kinetics and equilibrium studies. Bioresource Technology 100, 186-193.

Bayramoglu, G., Arica, M.Y., 2008. Enzymatic removal of phenol and p-chlorophenol in enzyme reactor: horseradish peroxidase immobilized on magnetic beads. Journal of Hazardous Materials 156, 148-155.

Bayramoglu, G., Yilmaz, M., Arica, M.Y., 2004. Evaluation of lysozyme adsorptive behavior of pHEMA-based affinity membranes related to the surface energy and its components to be used in chromatographic fields. Colloids and Surfaces A: Physicochemical and Engineering Aspects 243, 1121.

Calace, N., Nardi, E., Petronio, B.M., Pietroletti, M., 2002. Adsorption of phenols by paper mill sludges. Environmental Pollution 118, 315-319.

Dunlap, C.A., Biresaw, G., Jackson, M.A., 2005. Hydrophobic and electrostatic cell surface properties of blastospores of the entomopathogenic fungus Paecilomyces fumosoroseus. Colloids and Surfaces B: Biointerfaces 46, 261-266.

Hallenbeck, W.H., Cunningham, K.M., 1986. Quantitative Risk Assessment for Environmental and Occupational Health. Burns Lewis Publishers.

Ho, Y.S., 2006. Second-order kinetic model for the sorption of cadmium onto tree fern: a comparison of linear and non-linear methods. Water Research 40, 119125.

Kennedy, K.J., Lu, J.H., Mohn, W.W., 1992. Biosorption of chlorophenols to anaerobic granular sludge. Water Research 26, 1085-1092.

Li, H., Xu, M., Shi, Z., He, B., 2004. Isotherm analysis of phenol adsorption on polymeric adsorbents from nonaqueous solution. Journal of Colloid and Interface Science 271, 47-54.

Mukhopadhyay, M., 2008. Role of surface properties during biosorption of copper by pretreated Aspergillus niger biomass. Colloids and Surfaces A: Physicochemical and Engineering Aspects 329, 95-99.

Naja, G., Mustin, C., Berthelin, J., Volesky, B., 2005. Lead biosorption study with Rhizopus arrhizus using a metal-based titration technique. Journal of Colloid and Interface Science 292, 537-543.
Navarro, A.E., Portales, R.F., Sun-Kou, M.R., Llanos, B.P., 2008. Effect of pH on phenol biosorption by marine seaweeds. Journal of Hazardous Materials 156 (1-3), 405-411.

Quan, X., Shi, H., Zhang, Y., Wang, J., Qian, Y., 2004. Biodegradation of 2,4dichlorophenol and phenol in an airlift inner-loop bioreactor immobilized with Achromobacter sp.. Separation and Purification Technology 34, 97-103.

Ra, J.S., Oh, S.-Y., Lee, B.C., Kim, S.D., 2008. The effect of suspended particles coated by humic acid on the toxicity of pharmaceuticals, estrogens, and phenolic compounds. Environment International 34, 184-192.

Redlich, O.J., Peterson, D.L., 1959. A useful adsorption isotherm. The Journal of Physical Chemistry 63, 1024-1026.

Ritchie, A.G., 1997. Alternative to the Elovich equation for kinetics of adsorption of gases on solids. Journal of the Chemical Society, Faraday Transactions 73, 16501653.

Rostami, K.H., Joodaki, M.R., 2002. Some studies of cadmium adsorption using Aspergillus niger, Penicillium austurianum, employing an airlift fermenter. Chemical Engineering Journal 89, 239-252.

Sampedro, I., Marinari, S., D’Annibale, A., Grego, S., Ocampo, J.A., García-Romera, I., 2007. Organic matter evolution and partial detoxification in two-phase onative mill waste colonized by white-rot fungi. International Biodeterioration \& Biodegradation 60 (2), 116-125.

Tepe, O., Dursun, A.Y., 2008. Combined effects of external mass transfer and biodegradation rates on removal of phenol by immobilized Ralstonia eutropha in a packed bed reactor. Journal of Hazardous Materials 151, 9-16.

van Oss, C.J., 2003. Long-range and short-range mechanisms of hydrophobic attraction and hydrophilic repulsion in specific and aspecific interactions. Journal of Molecular Recognition 16, 177-190.

Wu, J., Yu, H.-Q., 2007. Biosorption of 2,4-dichlorophenol by immobilized white-rot fungus Phanerochaete chrysosporium from aqueous solutions. Bioresource Technology 98, 253-259.

Zeng, G., Huang, D., Huang, G., Hu, T., Jiang, X., Feng, C., Chen, Y., Tang, L., Liu, H., 2007. Composting of lead-contaminated solid waste with inocula of white-rot fungus. Bioresource Technology 98, 320-326. 